\title{
Qualitative theory testing by deductive design and pattern matching analysis.
}

\author{
Vargas-Bianchi, L. \\ Instituto de Investigación Científica, Universidad de Lima \\ Methodological note \\ Ivargas@ulima.edu.pe (corresponding author) \\ orcid: 0000-0002-9027-7673 \\ Citation: \\ Vargas-Bianchi, L. (2020). Qualitative theory testing by deductive design and pattern matching analysis. \\ SocArxiv https://doi.org/10.31235/osf.io/w4gxe
}

Summary: This methodological note describes a qualitative design suitable for testing theories and theoretical models, using a deductive procedure and the pattern matching analysis technique. In this approach the researcher formulates a set of theory-based propositions and compares them with the empirically observed outcomes.

Keywords: qualitative design, deductive qualitative, pattern matching, theory testing

It is possible to test a theory through a qualitative method by using a particular design and analysis technique. A theory testing is adequate to determine whether a theory -or theoretical model or framework- depends on a specific context (i.e., cultural, social or temporal), or has the capability of explaining a phenomenon in other situations, and to identify if the theory is generalizable or transferable to a different context from which they originally constituted it (Yin, 2018).

Generalization in an investigation refers to the requirement to demonstrate that a theory not only explains the phenomena in the context in which it was studied, but beyond the limit of that study (Farquhar \& Deigh, 2016). Despite obtaining generalizable findings is not a requirement of qualitative studies -as many of which are deployed because of interest in a particular case, or to know phenomena that occur in specific contexts (Hammersley, 2002)various authors point out it is possible that, under an adequate methodological approach, it's possible to get results that explain cases belonging to events different from which they originated (Carminati, 2018; Firestone, 1993; Lucas, 2003; Spillman, 2014; Yin, 2016). This is labeled as transferability (Graneheim \& Lundman, 2004; Malterud, 2001; Slevin \& Sines, 2013). For example, a model or theory, developed with a qualitative design in a specific reality and time, could ease the explanation and analysis of a similar case in a different place and circumstance. Onwuegbuzie \& Leech (2010) have identified that, even without stating it as part of their design, various qualitative studies carry out one of the two generalizations: 
analytical generalizations or transfer from case to case. Analytical generalizations apply to theories when they show that selected cases fit the general construction of a theory. Case-tocase transfer notes the possibility of making generalizations from one case to another case that share similar context or characteristics.

The qualitative deductive method is an adequate procedure to analyse a theory through testing and reviewing of the theory's results (Creswell, 2007; Hyde, 2000; Løkke \& Sørensen, 2014; Miller \& Crabtree, 2005; Bitektine, 2008). This method requires the researcher to work on an existing theory, collect empirical data to prove it, and reflect on its confirmation (or rejection) grounded by the findings (Creswell, 2014). The qualitative deductive method recquires to empirically collect data guided by the underlying theory, to later seek if observations fit the theory.

Pattern matching is a technique introduced by Campbell (1975), who argued that a singlecase study design could be solid proof of a theory as long as the set of expectations deduced from that theory can prove true in that case. In the pattern matching design, the researcher links the data from his study with the propositions that articulate the theory he is trying to prove (Campbell, 1975; Hyde, 2000; Sinkovics, 2017; Trochim, 1985), by comparing a pattern of observed results regarding another pattern of expected values derived from the theory under test (Bitektine, 2008). Hak and Dun (2010) call both ends of the information as "expected pattern" and "observed pattern", adding that theories predict the patterns of expected variables, which are considered hypotheses. Yin (2018) argues that when the patterns empirically found coincide with the expected patterns, the result contributes to confirm the derived hypotheses from the theory under review, and thus strengthen its validity. Conversely, when the expected and observed patterns do not coincide, it is necessary to examine alternative explanations for the hypotheses. One option is to contrast the reviewed theory with a rival theory, from which to falsify the former (Hyde, 2000; Yin, 2018).

Almutairi, Gardner, \& McCarth (2014) state that there is still little literature that explains how to apply pattern matching techniques. Some of these studies, such as works by Lee \& Mitchell (1996), Sinkovics, Sinkovics \& Yamin (2014), or Hyde (2000), present qualitative approach studies in which a pattern matching technique has been used. Despite the scarce literature on pattern matching, researches using this design describe and follow a common procedure. This procedure is descibed in the three steps that follow:

1. The initial step is theorizing, which leads to the definition of the expected theoretical pattern that will be tested (Sinkovics, 2017). This initial process can have different sources: a pre-existing theory or theoretical model already reported in previous research, or it can be grounded on the ideas and experiences of the researcher, or on the perspectives of people related to a phenomenon under study, it can even be a combination of all (Almutairi et al., 2014; Sinkovics, 2017).

2. The following step involves the translation of these theory or model into specific theoretical patterns, which can be conceptualized as hypotheses of propositions. These will serve as the expected patterns or predicted observations. This stage may 
include an alternative explanation for the expected observations (Hyde, 2000; Sinkovics, 2017; Trochim, 1985).

3. The last step is the empirical procedure of the technique, in which the researcher collects data from various relevant sources and analyses it to discover the degree to which data from the studied phenomenon fit with the tested theory. A codebook containing the theoretical propositions may be used to analyse the recollected empirical data and the tested theory for pattern matches (Fereday \& Muir-Cochrane, 2006; Pearse, 2019; Stuckey, 2015; Yukhymenko et al., 2014).

Depending on the researcher's scope and objectives, he can either inductively build a datadriven analytical framework, or collect data based on an already established theoretical framework for action. After data recollection, the observations are analyzed by identifying the fitness between the observed pattern and the expected pattern, to test the theory's validity (Bitektine, 2008; Hak \& Dul, 2010; Sinkovics, 2017; Trochim, 1985; Yin, 2018).

The method is suitable to examine any theoretical field, particularly those in preliminary stages of elaboration, or in those among which the existing knowledge is still partial (Bitektine, 2008; Creswell, 2007; Sinkovics, 2017).

\section{References}

Almutairi, A. F., Gardner, G. E., \& McCarthy, A. (2014). Practical guidance for the use of a pattern-matching technique in case-study research: A case presentation. Nursing \& Health Sciences, 16(2), 239-244. https://doi.org/10.1111/nhs.12096

Bitektine, A. (2008). Prospective case study design: qualitative method for deductive theory testing. Organizational research methods, 11(1), 160-180.

Campbell, D. T. (1975). "Degrees of Freedom" and the Case Study. Comparative Political Studies, 8(2), 178-193. https://doi.org/10.1177/001041407500800204

Carminati, L. (2018). Generalizability in Qualitative Research: A Tale of Two Traditions. Qualitative Health Research, 28(13), 2094-2101.

Creswell. (2014). Research Design: Qualitative, Quantitative, and Mixed Methods Approaches. SAGE Companion. Sage Publications.

Creswell, J. W. (2007). Qualitative inquiry \& research design: choosing among five approaches (3rd ed.). Sage.

Farquhar, J., \& Deigh, L. (2016). Living dangerously: generalizing in case study research. In Celebrating America's Pastimes: Baseball, Hot Dogs, Apple Pie and Marketing? (pp. 993997). Springer, Cham. 
Fereday, J., \& Muir-Cochrane, E. (2006). Demonstrating rigor using thematic analysis: A hybrid approach of inductive and deductive coding and theme development. International journal of qualitative methods, 5(1), 80-92.

Firestone, W. A. (1993). Alternative Arguments for Generalizing From Data as Applied to Qualitative Research. Educational Researcher, 22(4), 16-23. https://doi.org/10.3102/0013189X022004016

Graneheim, U. H., \& Lundman, B. (2004). Qualitative content analysis in nursing research: concepts, procedures and measures to achieve trustworthiness. Nurse Education Today, 24(2), 105-112. https://doi.org/10.1016/j.nedt.2003.10.001

Hak, T., \& Dul, J. (2010). Pattern Matching. In A. J. Mills, G. Durepos, \& E. Wiebe (Eds.), Encyclopedia of Case Study Research (pp. 664-665). Sage Publications.

Hammersley, M. (2002). The relationship between qualitative and quantitative research: paradigm loyalty versus methodological eclecticism. In J. T. Richardson (Ed.), Handbook of Qualitative Research Methods for Psychology and the Social Sciences (pp. 159-174). Oxford: BPS Blackwell.

Hyde, K. F. (2000). Recognising deductive processes in qualitative research. Qualitative Market Research: An International Journal, 3(2), 82-90. https://doi.org/10.1108/13522750010322089

Lee, T. W., Mitchell, T. R., \& Fireman, S. (1996). The Unfolding Model of Voluntary Employee Turnover. Academy of Management Review, 39(1), 5-36. https://doi.org/10.5465/amr.1994.9410122008

Løkke, A. K., \& Sørensen, P. D. (2014). Theory Testing Using Case Studies. Electronic Journal of Business Research Methods, 12(1).

Lucas, J. W. (2003). Theory-Testing, Generalization, and the Problem of External Validity. Sociological Theory, 21(3), 236-253. https://doi.org/https://doi.org/10.1111/14679558.00187

Malterud, K. (2001). Qualitative research: standards, challenges, and guidelines. The Lancet, 358(9280), 483-488. https://doi.org/10.1016/S0140-6736(01)05627-6

Miller, W. L., \& Crabtree, B. F. (2005). Clinical Research. In N. K. Denzin (Ed.), The Sage handbook of qualitative research (3rd ed., pp. 605-639). Thousand Oaks: Sage Publications.

Onwuegbuzie, A. J., \& Leech, N. L. (2010). Generalization practices in qualitative research: a mixed methods case study. Quality \& Quantity, 44(5), 881-892.

https://doi.org/10.1007/s11135-009-9241-z 
Pearse, N. (2019). An Illustration of Deductive Analysis in Qualitative Research. In A. Stacey (Ed.), ECRM 2019 18th European Conference on Research Methods in Business and . (pp. 264-268). Johannesburg: Academic Conferences and Publishing International Limited. https://doi.org/10.34190/RM.19.006

Sinkovics, N. (2017). Pattern matching in qualitative analysis. In C. Casell, A. Cunliffe, \& G. Grandy (Eds.), The Sage Handbook of Qualitative Business and Management Research Methods (p. 1056). Thousand Oaks: Sage Publications.

Sinkovics, N., Sinkovics, R. R., \& Yamin, M. (2014). The role of social value creation in business model formulation at the bottom of the pyramid - Implications for MNEs? International Business Review, 23(4), 692-707. https://doi.org/10.1016/J.IBUSREV.2013.12.004

Slevin, E., \& Sines, D. (2013). Enhancing the truthfulness, consistency and transferability of a qualitative study: utilising a manifold of approaches. Nurse Researcher, 7(2), 79-98. https://doi.org/10.7748/nr2000.01.7.2.79.c6113

Spillman, L. (2014). Mixed Methods and the Logic of Qualitative Inference. Qualitative Sociology, 37(2), 189-205. https://doi.org/10.1007/s11133-014-9273-0

Stuckey, H. L. (2015). The second step in data analysis: Coding qualitative research data. Journal of Social Health and Diabetes, 3(1), 7-10. https://doi.org/10.4103/23210656.140875

Trochim, W. M. K. (1985). Pattern Matching, Validity, and Conceptualization in Program Evaluation. Evaluation Review, 9(5), 575-604. https://doi.org/10.1177/0193841X8500900503

Yin, R. K. (2016). Qualitative Research from Start to Finish. New York: The Guilford Press.

Yin, R. K. (2018). Case Study Research Design and Methods (6th ed.). Los Angeles: Sage.

Yukhymenko, M. A., Brown, S. W., Lawless, K. A., Brodowinska, K., \& Mullin, G. (2014). Thematic Analysis of Teacher Instructional Practices and Student Responses in Middle School Classrooms with Problem-Based Learning Environment. Global Education Review, 1(1), 93-110. 